\title{
A dimensão espacial e dionisíaca da voz com base nas propostas de Francesca Della Monica: resgatando liberdade expressiva e identidade vocal
}

The spatial and Dionysian dimension of the voice based on the proposals of Francesca Della Monica: retrieving expressive freedom and vocal identity

Ernani de Castro Maletta ${ }^{1}$ 


\section{Resumo}

A partir de inquietações do autor sobre formação e criação vocal - técnica versus estética, restrição da voz a aspectos sonoros e apolíneos -, apresentam-se propostas da pesquisadora italiana Francesca Della Monica, com quem o autor estabeleceu parceria artístico-acadêmica, fruto de seu pósdoutorado. Expõem-se as bases filosóficas e metodológicas de Della Monica, destacando-se as dimensões espaciais da voz, em particular os espaços histórico e mítico e suas relações com a liberdade expressiva, identidade vocal e com a valorização da expressão dionisíaca da voz. O autor conclui afirmando a relevância da metodologia de Della Monica em especial para os processos de formação e criação cênicas.

Palavras-chave: espacialização da voz; expressão dionisíaca; liberdade expressiva; identidade vocal; Francesca Della Monica.

\section{Abstract}

Beginning from the author's restlessness towards vocal training and creation - technique versus aesthetics, restriction of the voice into sonorous and Apollonian aspects - proposals from the Italian researcher Francesca Della Monica, with whom the author carried out artistic-academic relationship, resulting from the author's post-doc program are presented. We describe Della Monica's philosophical and methodological bases, highlighting the spatial dimensions of the voice, in particular the historical and mythical spaces and its relations with the expressive freedom, vocal identity together with the assignment of values to the Dionysian expression of the voice. In conclusion, the author points out the relevance of Della Monica's methodology, especially in the processes of formation and creation of performing arts.

Keywords: voice spatialization; Dionysian expression; expressive freedom; vocal identity; Francesca Della Monica.

ISSN: 1414.5731

Universidade Federal de Minas Gerais (UFMG). Prof. Dr. do Programa de Pós-Graduação em Artes. Belo Horizonte (MG). ernanimaletta@gmail.com 


\section{Inquietações}

Entre tantas inquietações que sempre me acompanharam em meu percurso artístico e acadêmico, no que se refere ao trabalho vocal em cena - seja em processos criativos dos quais participei, seja em outros que tive a oportunidade de observar -, algumas se colocaram em primeiro plano. Em primeiro lugar, destaco a tendência que, em minha opinião, existe em se vincular as propostas técnicas às escolhas estéticas, somada à dificuldade que geralmente se tem em adequar as propostas técnicas às peculiaridades das pessoas, levando, ao contrário, as pessoas a se adequarem à técnica e, consequentemente, a reproduzir modelos e a abrir mão de parte de sua identidade.

Ao experimentar as mais diversas propostas técnicas para a formação e criação vocal voltadas à cena desde os anos 1980, apresentadas por artistas e pesquisadores de diferentes nacionalidades, experiências e formações, sempre as percebia à serviço de uma estética específica, vinculadas a discursos teatrais e a projetos de encenação frutos de pesquisas particulares, que acabavam por conduzir os participantes e interessados ao desenvolvimento ou ao aprimoramento de habilidades vocais direcionadas a resultados específicos. Isso se mostrava muito eficiente e satisfatório para quem se interessava em abraçar determinados ideais estéticos, mas não me ajudava, como professor, a contribuir na formação de um grupo de alunos bastante heterogêneo no que diz respeito a esses ideais.

Conviver com essa heterogeneidade é a minha realidade desde meus primeiros trabalhos no Teatro, como professor e como diretor-preparador vocal e musical, pois, a cada processo de formação e/ou criação artística do qual participava, eu me encontrava a serviço de um ideal estético diferente e que exigia dos atores uma resposta vocal e/ou musical específica. No que se refere às questões musicais, desenvolvi uma metodologia voltada à atuação cênica e bastante peculiar, totalmente desvinculada de ideais estéticos, fruto de quase trinta anos de pesquisa e prática artística - e que hoje me identifica como professor e artista -, para que os atores, independentemente de qualquer formação musical, pudessem cantar arranjos vocais e tocar instrumentos, como discurso cênico, não por meio de um virtuosismo técnico individual, mas, ao contrário, aproveitando seus limites e especificidades. Valoriza-se, assim, a colaboração e o potencial artístico do coletivo, o que permite minimizar ou eliminar as dificuldades técnicas que individualmente os atores não poderiam enfrentar.

Quanto às questões vocais individuais, seja no canto ou na fala, a cada processo a regra era buscar uma condução técnica específica, coerente com a estética de encenação proposta e, por isso, única para todos os artistas envolvidos, que se adequavam a ela, muitas vezes em detrimento da sua identidade vocal. Como professor da área de Estudos Vocais e Musicais do Curso de Graduação em Teatro da Universidade Federal de Minas Gerais, a realidade com a qual me deparei foi significativamente mais complexa, tendo em vista que esse curso, por não se vincular a um referencial estético específico, propõe-se a discutir e praticar o Teatro em suas diversas possibilidades, recebendo alunos que, em sua maioria, não se vincularam a nenhum pensamento estético e nem têm ideia se o farão. Por isso, mereceriam uma abordagem de formação técnica que pudesse sustentar, posteriormente, propostas estéticas diversas. 
Na descrença da existência de uma abordagem técnica para a voz cênica que não fosse estetizante e na tentativa contínua de não me vincular, como professor, a qualquer estética específica, construí, no decorrer de minha carreira, um mosaico pedagógico, uma colcha metodológica de retalhos que, se por um lado me ajudavam a apresentar aos alunos um panorama com diversas possibilidades para o trabalho vocal, por outro me tornavam um portador de vozes, entre as quais eu não percebia, com clareza, a minha própria. Na dialética do processo artístico-pedagógico, eu conseguia reunir e apresentar um conjunto de vozes teses e vozes antíteses, mas não percebia com clareza a minha síntese polifônica.

Outra inquietação que me impulsionou à discussão aqui proposta diz respeito a uma questão conceitual. As definições de voz humana que se encontram, seja em dicionários linguísticos ou do campo das ciências médicas, reduziram-na apenas ao seu aspecto sonoro - o que talvez justifique o surgimento de questões, que considero desnecessárias, sobre uma "integração" entre corpo e voz, como se esta fosse um fenômeno dissociado do corpo. Entretanto, em seu sentido mais amplo, voz significa manifestação do pensamento, a expressão de um ponto de vista particular, de uma individualidade, qualquer que seja o veículo usado para tal. Portanto, voz não é exclusiva nem necessariamente um fenômeno sonoro.

Penso que essa definição seja justa também para a voz humana que, além do som produzido pela vibração das pregas vocais, deve obrigatoriamente incluir a manifestação de partes ou mesmo de todo o corpo humano (olhos, movimentos faciais, mãos, braços e qualquer outro gesto, movimento ou possibilidade expressiva corpórea) que, como um todo, é imprescindível para expressar os pensamentos, os desejos, as necessidades e os pontos de vista do sujeito fonador. Dessa forma, a voz humana compreende integralmente o ser humano, por meio do som e do movimento expressivo de seu corpo - o que torna sem sentido a questão "integração corpo e voz" que, na verdade, desintegra o fenômeno vocal, separando o som do conjunto corporal que o produz.

Uma última inquietação que aqui destaco se refere à tendência predominante em se valorizar o desenvolvimento técnico das possibilidades apolíneas da expressão vocal, o que me parece incongruente com uma cena contemporânea na qual o som da voz está, de forma evidente, a serviço da manifestação dos aspectos não verbais do discurso vocal, intrinsecamente ligados à sua expressão dionisíaca. A respeito disso, De Marinis ressalta, como uma grande novidade do século XX, a utilização da forma poética como referência para a composição teatral, não no sentido de encenar uma poesia, mas de fazer da cena uma manifestação poética. Para tanto, ele evidencia a importância da exploração dionisíaca da voz como grito, balbucio, sussurro, gemido, resmungo, uivo, onomatopeia e como instrumento musical. (De Marinis, 2011, p. 12).

Afrontar essas inquietações e descobrir estratégias de trabalho que pudessem redefinir minha atuação como pesquisador, professor e artista, foi o que me proporcionou o meu encontro com a pesquisadora italiana Francesca Della Monica - com quem realizei, em 2010-2011, um projeto de pós-doutorado e com quem estabeleci, desde então, uma parceria artístico-acadêmica. ${ }^{2}$

${ }^{2}$ Estágio Pós-Doutoral no Exterior, contemplado com bolsa CAPES, com as colaborações do Prof. Marco De Marinis, da Università di Bo- logna (supervisor do projeto), e de Francesca Della Monica (sujeito da pesquisa). 
Francesca Della Monica, também artista e pedagoga, conduz uma pesquisa original sobre as diversas possibilidades da voz e da musicalidade no âmbito teatral contemporâneo, por meio de uma metodologia própria. Há muitos anos, colabora com importantes companhias e instituições teatrais italianas, em particular a Fondazione Pontedera Teatro - onde trabalha como artista-pesquisadora convidada, como docente e como coordenadora de projetos de formação vocal - e a Compagnia Lombardi-Tiezzi, dirigida pelo renomado artista Federico Tiezzi.

Della Monica possui uma formação privilegiada, que abrange Filosofia, Arqueologia, Música, Teatro e Artes Visuais. Graduou-se em Musica da Camera per Cantanti, no Conservatorio L. Cherubini di Firenze (1987); em Canto, no Conservatorio L. Frescobaldi di Ferrara (1989); e em Filosofia, na Università degli Studi di Siena (1990). Em 1993, nessa mesma universidade, concluiu sua especialização em Arqueologia. Absorvendo um sólido conhecimento tanto das técnicas tradicionais quanto das experiências experimentais e de vanguarda, é considerada uma das maiores especialistas na Europa, seja pelo aspecto técnico quanto pelo criativo. A respeito disso, Silvio Castiglioni - pesquisador de Teatro com intensa atuação como formador artístico na Itália e em outros países, diretor do Festival Santarcangelo dei Teatri, um dos mais importantes eventos internacionais dedicados à cena contemporânea - diz que Della Monica "desenvolve uma metodologia de trabalho profunda e articulada, simples e ao mesmo tempo completa: uma proposta de grandíssimo valor, único no panorama atual da didática ligada à vocalidade". 3

O particularíssimo percurso artístico de Della Monica é marcado pelo rompimento com as convenções que limitam nosso potencial expressivo. Daí vem a sua predileção pelo estudo das notações não convencionais da voz, próprias da música contemporânea, que a conduziu a colaborações significativas. Destaca-se seu encontro com John Cage, que compôs e adaptou alguns solos para a sua voz. Gravou dois CDs dedicados à música de Cage, um dos quais apresenta a gravação ao vivo de um concerto realizado em Firenze, em 1992, com a presença do autor. Em 2012, em função de seu virtuosismo técnico-expressivo, gravou a convite de Pierre Boulez canções inéditas por ele compostas com o objetivo de explorar ao máximo as possibilidades da voz solo. Atualmente, representa a Itália no âmbito da Instituição Giving Voice of Wales, um dos mais importantes organismos de pesquisa europeia sobre os estudos voltados à vocalidade.

Paralelamente ao trabalho artístico, Della Monica é professora da Accademia di Belle Arti di Brera (Milão/Itália), onde desenvolve um trabalho essencialmente polifônico por meio da disciplina pela qual é responsável, Audiovisivi lineari, propondo o contraponto entre o discurso sonoro e o visual, por meio do estudo dos ritmos e dos tempos na criação de paisagens sonoras, da sinestesia na percepção das realidades acústica e visual, da acústica vocal nos diferentes ambientes e da análise do diálogo entre som e imagem nos processos de composição da dramaturgia musical em diferentes contextos artísticos.

\footnotetext{
${ }^{3}$ Depoimento obtido em entrevista realizada por ocasião de minha pesquisa de doutorado. visor do projeto), e de Francesca Della Monica (sujeito da pesquisa).
} 
A partir de 2011, em função da consolidação da parceria que com ela estabeleci, Della Monica vem desenvolvendo relevantes e contínuos trabalhos no Brasil, em especial com o diretor Gabriel Villela - com quem já montou os espetáculos Hécuba (de Euripides), Macbeth (de Shakespeare) e Os Gigantes da Montanha (de Pirandello) -, e com os grupos Galpão (Belo Horizonte/MG) e Clowns de Shakespeare (Natal/ RN). Integra o LiberaVox - Grupo de Pesquisa sobre a Vocalidade e a Musicalidade da Polifonia Cênica, por mim liderado e registrado no CNPq, por meio do qual tem oferecido inúmeros laboratórios e oficinas sobre as suas propostas de trabalho com a voz e tem estreitado seu contato com a academia brasileira.

Ao percebermos nossas muitas afinidades artísticas e pedagógicas, propusemonos, a longo prazo, a desenvolver estratégias polifônicas pelo entrelaçamento dos nossos discursos metodológicos para o trabalho vocal e musical no Teatro. ${ }^{4}$ Esse encontro marca meu percurso profissional como um verdadeiro divisor de águas, na medida em que Della Monica foi capaz de me desvelar uma proposta de trabalho vocal que, simultaneamente:

- não se vincula a uma elaboração estética específica e, por isso, pode contribuir para todas elas;

- evidencia a dimensão corporal da ação vocal, para além dos seus aspectos sonoros;

- propõe e valoriza as dimensões espaciais da ação vocal;

- busca uma liberdade expressiva que nos permite ultrapassar um espaço vocal que ela chama de histórico, regido pelas convenções apolíneas, levando-nos ao alcance de um espaço vocal mítico, próprio das expressões dionisíacas.

Não por acaso uso acima o verbo desvelar, pois as tantas afinidades entre a metodologia de Della Monica para o trabalho vocal e aquela que desenvolvi para o trabalho musical fizeram-me perceber que muitas das suas ideias sempre me foram presentes, porém veladas pelo emaranhado de informações e teorias que fui colecionando. Essas afinidades permitiram-nos apropriar um do discurso do outro e assumi-lo como seu.

Apresentam-se, a seguir, alguns dos princípios, proposições e procedimentos de Della Monica, que contribuem para responder às questões acima levantadas. ${ }^{5}$

\section{A arqueologia vocal de Francesca Della Monica}

O termo arqueologia, como procedimento que busca o passado para se descobrir a origem das coisas por meio de objetos materiais que a revelam, é precisamente

\footnotetext{
${ }^{4}$ Nossa atuação, que teve início e se mantém na Itália, desdobrou-se em outras parcerias artísticas e pedagógicas no Brasil, em particular com o diretor Gabriel Villela e com os grupos Galpão, Clowns de Shakespeare e Voz\&Companhia.
}

${ }^{5}$ Essa e todas as demais proposições de Francesca Della Monica que compõem este artigo, com exceção daquelas para as quais se indicam explicitamente as referências bibliográficas, baseiam-se em depoimentos obtidos em entrevistas realizadas com a pesquisadora em 2010-2011, por ocasião do meu pós-doutorado, em cujo Relatório - (Maletta, 2011) - encontram-se registrados. 
apropriado para identificar suas propostas metodológicas. Por meio de procedimentos que ouso chamar de antitécnica, ela nos conduz a processos contínuos de libertação de uma voz que, com o passar dos anos, limitou-se às regras às quais somos levados a obedecer em nome da ordem social e do bem estar comum. Uso o termo antitécnica por considerar as técnicas, com as quais tive contato, um conjunto de procedimentos, com referenciais apolíneos, que em vez de libertarem nosso potencial vocal em suas peculiaridades, reforçam os limites impostos pelas convenções, buscam resultados estéticos específicos, impedindo a livre expressão. Francesca, arqueologicamente, levanos à reconexão com a memória sensorial do passado, quando ainda éramos livres para nos expressarmos corporalmente com todo potencial e particularidades.

É importante comentar que, por intermédio da Arqueologia, Della Monica desenvolveu a habilidade única e extraordinária de, pela audição, escavar o corpo de todos aqueles com quem trabalha. Desse modo, consegue perceber o fenômeno vocal de uma forma plena, entrelaçando polifonicamente uma percepção da voz ao mesmo tempo técnica e expressiva - ou melhor, mostra-nos que a técnica e a expressividade não se excluem; em vez disso, criam juntas um único conceito igualmente belo e complexo.

Das bases filosóficas e princípios fundamentais da proposta metodológica de Della Monica para o trabalho vocal no Teatro, cabe focalizar em primeiro lugar o estudo das dimensões espaciais da ação vocal, por se tratar do principal pilar que sustenta o seu pensamento sobre o tema aqui exposto.

\section{Os espaços da ação vocal}

Della Monica identifica diversos espaços que a voz deve ocupar, para que ação comunicativa seja plenamente efetivada:

- espaço físico visível - espaço concreto do ambiente no qual se está, e que pode ser fisicamente percebido por intermédio da visão. Corresponde à dimensão do presente, do imediato, do real;

- espaço físico possível - aquele também concreto, mas que não podemos ver: o espaço posterior e todos os outros que estão fora do nosso campo visual, mas que podemos enxergar por intermédio da memória. Corresponde a uma dimensão remota e da possibilidade;

- espaço relacional - espaço não concreto e que existe na medida em que estabelecemos uma relação de comunicação com o nosso interlocutor, incluindo-o como participante do discurso que estabelecemos e agindo de forma que a comunicação seja a mais efetiva possível, isto é, que o nosso interlocutor perceba com clareza o que queremos comunicar;

- espaço lógico-projetivo - aquele, também não concreto, que se refere à construção do discurso verbal, musical ou coreográfico, envolvendo a lógica interna daquilo que se pretende comunicar (Della Monica e Maletta, 2013, p. 69-71) 
Com base nessas definições, Della Monica analisa a problemática do que se costuma chamar de projeção vocal de forma peculiar e bastante esclarecedora. Projetar a voz não deveria ser, em hipótese alguma, uma questão de volume, de força, mas uma questão de espaço. Em vez de ganhar volume, deve-se pensar em ganhar espaço, em ampliá-lo, em emitir a voz mais distante de si mesmo. É a ocupação dos espaços, em todas as suas dimensões, que promove a plena utilização do potencial vocal.

O conceito de espacialização da voz vem solucionar um grave problema que é criado pela ideia de projeção. A partir da diferença entre a dimensão visível do espaço e suas outras dimensões, Della Monica identifica a peculiaridade de cada um desses termos, que torna limitadora a ideia da projeção. Para ela, entende-se por projeção a ação do direcionamento da voz em direção a um ponto ou a um setor espacial visível e bem definido, com a intenção mais ou menos consciente de fazer chegar a palavra, dita ou cantada, àqueles interlocutores que estão dentro desse campo de visão. Trata-se de um espaço predominantemente frontal e que exclui tudo e todos os que não são visíveis, fazendo com que a voz perca sonoridade, movimento e presença cênica, comprometendo a comunicação com os interlocutores.

Em vez disso, a espacialização se refere a uma reação corpórea infinitamente mais ampla, pois a voz, nesse caso, é direcionada a todas as outras dimensões do espaço e a todos os interlocutores possíveis, mesmo que não sejam visíveis. Com isso, ganha-se muito em sonoridade - uma vez que a espacialização da voz amplifica substancialmente os harmônicos secundários característicos de cada uma das vogais -, ganha-se em gestualidade, efetiva-se a comunicação e, consequentemente, ganha força a presença cênica. (Ibidem, p. 70)

A reação corpórea e mental aos espaços deveria se antecipar à emissão (gesto) vocal e permanecer além da duração do som ouvido, incluindo os silêncios e dando significado a eles. Tudo isso é evidente em um diálogo, no qual o espaço que liga os interlocutores existe por meio do alternar-se do dizer e do escutar. No espaço relacional, as leis das proxêmicas atuam significativamente, ou seja, a voz, como instrumento de comunicação, deve respeitar e ser coerente com a proximidade entre emissor e interlocutor. (Ibidem, p.70).

Della Monica se refere a quatro dimensões espaço-relacionais:

- íntima - quando há grande proximidade física entre emissor e pouquíssimos interlocutores, não se pretendendo incluir outros. Nesse caso, a ação vocal se limita a espaços restritos;

- privada - a ação vocal é direcionada a um grupo um pouco maior de interlocutores, que ocorre geralmente nas reuniões familiares, profissionais ou de amigos. O espaço relacional da voz se amplia e, consequentemente, provoca um aumento de extensão e de intensidade corporais;

- pública - a ação vocal é direcionada a grandes grupos, própria das salas de aula, auditórios, plateias teatrais, assembleias e comícios. O espaço vocal cresce consideravelmente e, como consequência, utilizam-se grandes extensões e intensidades; 
- mítica - refere-se à necessidade de manifestação vocal que vai além das convenções, para se expressarem afetos, emoções e desejos que fogem do controle das regras sociais. Usam-se extensões e intensidades extremas.

Cabe evidenciar que o aumento das extensões e intensidades deve ser uma consequência da ampliação do espaço vocal, e não o contrário. Partir de um aumento de intensidade da voz como recurso para a sua projeção quase sempre implica o uso de força excessiva, que causa desgaste, perda de espaço e de comunicação. $O$ impulso vocal, antes da emissão do som, começa com o contato de todo corpo com o espaço. Com isso, Della Monica simplifica sobremaneira a problemática da "relação corpo e voz", uma vez que, já a priori, rompe definitivamente com essa dicotomia. Ao se dizer o corpo de uma voz, não se está utilizando uma imagem metafórica, pois se trata, exatamente, do corpo integral da pessoa que produz essa voz, que não apenas participa, mas se coloca no espaço antes da emissão do primeiro impulso sonoro. Segundo ela, quando antecipo o som da voz, é a vitória do dever; quando a voz começa pela reação do corpo aos espaços, é a vitória da presença.

É também fundamental observar que o espaço se vê com todo o corpo e não apenas com os olhos. Perceber o espaço apenas com os olhos limita o corpo a ressonâncias prevalentemente frontais, enquanto sentir o espaço e então relacionar-se com a multiplicidade das dimensões acima descritas estende a ação ressonante do corpo a toda a sua superfície. Trata-se de disponibilizar todas as cavidades de ressonância do corpo à sua ação amplificadora, graças a uma reação ao espaço. De fato, a exposição a espaços de grandes dimensões e a horizontes remotos determina uma reação de abaixamento da laringe, já no momento do ataque vocal, como se o corpo aumentasse a própria disponibilidade e a própria receptividade, alargando os próprios limites para além do visível. (Ibidem, p. 70).

Logo no início do trabalho com a espacialização da voz, Della Monica cria a bela imagem poética de que a voz começa o seu percurso na outra margem do rio. Para tanto, sugere que imaginemos um rio, do qual estamos em uma das margens. $O$ corpo, mesmo que fisicamente permaneça nessa margem, projeta-se para a segunda, a partir da qual a voz inicia o seu percurso, em direção à terceira margem, numa alusão poética a Guimarães Rosa.

Para se efetivar plenamente a ideia de espacialização, essa e todas as imagens que se criam durante o trabalho vocal não devem estar apenas frontalmente, mas se espelhar em todas as outras direções espaciais - atrás, à direita, à esquerda, acima, abaixo. Mesmo que haja um interlocutor direto localizado em um espaço específico, deve-se considerar que a voz se movimenta sempre em direção a múltiplos outros interlocutores indiretos, que se distribuem em todas as direções. Depois do primeiro impulso sonoro - que já está do outro lado do rio -, cada nova nota ou sílaba executada dever estar sempre mais afastada da anterior, ou seja, do sujeito fonador e mais perto dos interlocutores.

Para o corpo estar em movimento, não é preciso mover-se fisicamente. Podese fazê-lo por meio da gestualidade vocal. Porém, durante os exercícios vocais, para promover uma relação mais concreta entre o gesto vocal, o corpo em sua totalidade e os espaços, para dar mais concretude ao fenômeno vocal e intensificar as imagens 
que se criam no decorrer do processo, Della Monica sugere que sejam feitos gestos, por meio do movimento dos braços, desenhando o percurso da voz que já começa do outro lado do rio e sempre caminha em direção aos interlocutores - isto é, o gesto vocal que começa na outra margem, não deve permanecer nela, mas continuar sempre em percurso.

Portanto, a não ser que seja um objetivo expressivo, deve-se evitar que a voz, ao iniciar seu movimento envolvendo as diversas dimensões do espaço, faça um percurso de retorno ao sujeito fonador, ou então que o percurso gestual da voz reproduza o movimento lógico interno da frase, tanto cantada quanto falada, que muitas vezes carrega a ideia de que há um movimento de afastamento ou crescimento de intensidade até a sua metade, seguida de um retorno ao ponto de partida. Devemos, então, estar atentos, de modo a não permitir que o percurso da voz reproduza necessariamente esse movimento. Além disso, ao se começar a segunda parte da frase, uma nova frase ou um novo trecho da narrativa, é muito comum a perda do espaço inicialmente conquistado, com o retrocesso do gesto vocal para o espaço mais íntimo ao sujeito fonador.

Em suma, o movimento vocal, como gesto de relação, não deve se conter no espaço em torno ao emissor ou voltar-se para o interior dele, mas, por meio da ampliação desse espaço, deve se afastar da margem na qual o emissor se referencia e fala apenas de si mesmo, em busca da comunicação com o outro. Nesse espaço ampliado de comunicação, devem ser incluídos todos os interlocutores, não cabendo um gesto vocal que se comunica com apenas um deles e que exclui os outros. Para isso, antes de começar a dizer, a cantar, a gritar, a sussurrar..., o corpo mede distâncias, engloba alteridades, estabelece trajetórias e o transporte do gesto. Isso deve ocorrer antes do ataque sonoro e é por isso que cada ação vocal, ao mesmo tempo em que comporta alturas, intensidades e timbres, compreende também espaços, proxêmicas, inclusões e exclusões.

Quanto ao espaço lógico-projetivo, observa-se que, para as pessoas que não têm o hábito de articular o próprio pensamento e, portanto, o próprio discurso verbal de forma hipotética e condicional, não é raro que encontrem dificuldade em manter a voz direcionada para frente e em movimento, até o final da frase. É como se o corpo se fechasse antes do fim do discurso, porque não está habituado a perceber a importância e a amplitude da tradução espacial que a lógica da fala comporta. A mesma falta de hábito explica a insuficiência de fôlego na sustentação da emissão.

O espaço lógico-projetivo, por exemplo, refere-se à significativa diferença espacial que existe entre os modos indicativo e subjuntivo: o primeiro corresponde a espaços mais limitados, uma vez que a dimensão temporal está localizada exclusivamente no presente, exclusivamente no passado ou exclusivamente no futuro; no caso do subjuntivo, são colocadas em relação dimensões temporais diferentes. (Ibidem, p. 71-72).

Della Monica defende, como imprescindível, a absoluta clareza e inteligibilidade do que se diz, de modo que uma expressão recorrente em seu trabalho é primeiro a palavra, depois o som, isto é, não se deve abrir mão da clareza e inteligibilidade daquilo que se diz, em função de uma qualidade sonora específica. Também em busca dessa precisão comunicativa, outra orientação que constantemente ela nos dá é a de 
que cada exercício vocal, por mais simples que seja, deve ser realizado como uma pequena dramaturgia.

Além de todas as questões acima consideradas, entre as outras dificuldades que se enfrentam na criação vocal cênica, diretamente relacionadas à falta de espaço, Della Monica evidencia a problemática das limitações expressivas a que se é submetido para se viver em comunidade e se adequar às regras de convivência e às convenções do que é socialmente considerado certo ou errado. Isso se reflete intensamente na extensão vocal, na liberdade expressiva e, consequentemente, na perda da identidade vocal, na medida em que se elegem modelos a serem seguidos, quase que exclusivamente apolíneos, que implicam a repressão de características e procedimentos singulares, possivelmente dionisíacos, que fujam das convenções sociais.

A respeito desse tema, Della Monica nos apresenta as noções de espaço histórico e espaço mítico, focalizados a seguir.

\section{A busca da liberdade expressiva para o resgate da identidade da voz e a valorização de sua dimensão dionisíaca}

As possibilidades que tem a criança recém-nascida de sempre manifestar corporal e plenamente seus desejos, suas necessidades, independentemente do lugar, do momento e das circunstâncias em que se encontra, diminuem de forma progressiva a partir do momento em que é considerada "apta" a obedecer regras sociais - em especial quando aprendemos a falar e a andar, pois deve-se a todo custo evitar que alguns desejos, necessidades e ideias sejam expressos no momento errado, no lugar errado, da forma errada ou para as pessoas erradas.

$\mathrm{Na}$ verdade, passamos a conviver com uma contradição que nos acompanha pelo resto da vida: à medida que o nosso potencial expressivo cresce continuamente com a aquisição de habilidades que nos permitem manifestar mais plenamente os nossos desejos e necessidades, perdemos em igual ou maior proporção a nossa liberdade expressiva, em nome das convenções sociais que ditam quando, como ou se podemos manifestá-los.

Paradoxalmente, quando aprendemos a falar, começamos a perder a nossa voz, em seu sentido mais amplo. Muitas pessoas sofrem repressões de forma tão contínua, intensa e por vezes assustadora que acabam até mesmo se privando de manifestações expressivas que lhes seriam permitidas. Isso porque passamos a habitar um espaço que Della Monica chama de histórico, predominantemente apolíneo, no qual aprendemos a nos expressar de uma forma convencional e equilibrada, não perturbada pelos afetos e emoções. Os pontos de vista particulares e as individualidades são geralmente reprimidos pelas regras massificadoras da vida em sociedade e os possiveis transgressores são quase sempre punidos, suas expressões são identificadas como pecados ou incivilidade, nos quais é inculcada a culpa por tê-los cometido. Assim, as ações (gestos) vocais ficam restritas a espaços reduzidos.

A conquista da liberdade vocal e da possibilidade de manifestar as individualidades, independentemente das noções apolíneas de certo e errado, significa o alcance do espaço mítico, dionisíaco e polifônico. Nesse espaço, segundo Della Monica, a voz de cada indivíduo, em meio ao terremoto das emoções, das paixões, 
preserva o seu poder expressivo. A verbalidade cede o primado à extraverbalidade, de modo que o como se diz é mais importante que o que se diz. Então, o recinto gestual multiplica a sua amplitude e o mythus pode encontrar a sua representação. (Della Monica e Maletta, 2013, p. 72)

Esses espaços da história e do mito estão diretamente relacionados à extensão e à intensidade do som da voz. Ao nos limitarmos ao espaço (reduzido) da história, a região média das alturas e as intensidades moderadas são suficientes para a expressão da voz, dos desejos e necessidades que, nesse caso, estão delimitados e controlados. Alcançar o espaço do mito implica, inevitavelmente, atingir as regiões, até mesmo extremas, dos agudos e dos graves, assim como intensidades fortes, para muito além do nosso hábito cotidiano. As dinâmicas limitadas da voz histórica tornam-se hiperbólicas na voz mítica, envolvendo, juntamente ao espaço, as alturas e as intensidades. (Ibidem, p. 72).

Uma alegoria que contribui para uma melhor compreensão da passagem do espaço histórico ao mítico são cercas circulares imaginárias que se constroem ao nosso redor e que definem uma área limitada, dentro da qual estamos no espaço histórico e "protegidos" pelas convenções sociais. Ultrapassar a cerca significa transgredir as regras e alcançar o espaço mítico.

Della Monica, recorrentemente, sugere outra imagem: as Colunas de Hércules, a serem ultrapassadas. Tomar essa atitude não é nada fácil, pois, à medida que nos aproximamos das cercas/colunas, em direção ao desconhecido espaço da liberdade expressiva - isto é, à medida que nos afastamos da região do (falso) conforto, próprio do espaço das convenções -, a nossa tendência é perceber tal ação como causadora de um perigo iminente, muitas vezes assustador, que geralmente nos faz frear e abrir mão da expressão do desejo.

Por isso, quando cantamos, é muito comum enfrentar dificuldades na passagem da região média grave para a média aguda, pois é exatamente nesse ponto que encontramos nossas cercas/colunas de Hércules. Na vida cotidiana, usa-se a voz até uma certa altura. A partir daí, tem-se medo de enfrentar um novo espaço. Della Monica, a respeito disso, é categórica, afirmando que não se atinge o agudo por falta de espaço. Segundo ela, o agudo, de uma forma antropológica, exige mais espaço, jamais força.

O mesmo vale para outras tantas dificuldades na emissão, especialmente à falta de precisão na afinação e ao que se costuma chamar de quebras da voz, isto é, o rompimento do fluxo contínuo do som vocal. Sair do nosso conhecido recinto pode ser tão assustador que, mesmo quando nossos desejos expressivos não cabem nele, preferimos nos espremer, apertar. Assim, o receio do desconhecido impede o movimento sonoro da voz em direção à região dos agudos - o que também vale para as extremidades graves -, levando-nos a abrir mão da própria identidade vocal e mascarar tecnicamente a voz para alcançar essas regiões de acordo com as regras sociais ou com determinadas estéticas por estas legitimadas. Esse é um bom exemplo de como a técnica pode ser limitadora.

Para a preservação da identidade vocal do sujeito fonador deve-se buscar uma qualidade sonora que seja própria da sua pessoa vocal, que verdadeiramente o identifique e que seja mantida em toda a sua extensão, não se alterando na passagem da fala para o canto. Para tanto, Della Monica se dedica às seguintes questões: 
- significado da extensão vocal na voz falada e cantada, em suas dimensões íntima, privada, pública e mítica, tanto na expressão verbal quanto na extraverbal;

- significado das passagens de registro vocal;

- relações entre extensão vocal e homogeneidade fônica;

- estudo dos parâmetros e das dinâmicas musicais a partir do material fônico que forma a palavra, isto é, as funções e as peculiaridades vocálica e consonantal, a articulação e o significado equilíbrio vocálico-consonantal no fonema, na palavra e na gestualidade vocal;

- relações entre personalidade vocal e entonação;

- relações entre entonação, espaço, velocidade gestual, intensidade e entre movimento gestual e movimento musical;

- modalidades diversas da desafinação e sua interpretação;

- relações entre som e palavra na entonação.

As contribuições de Francesca Della Monica abrangem certamente muitas outras questões. Em particular, caberia aqui focalizar o trabalho que ela propõe sobre o texto dramático, ao mesmo tempo linguístico e filosófico, que é anterior a qualquer exercício de interpretação. Por intermédio de uma cuidadosa análise, tanto morfológica quanto sintática, também similar a um processo arqueológico, evidenciam-se as funções das palavras na construção da frase, buscando-se uma compreensão efetiva do texto que, uma vez alcançada, exige inevitavelmente as alterações de dinâmica, de andamento, a utilização adequada das pausas, variações de ritmo e de entonação. No entanto, uma análise mais detalhada desse tema, bem como daqueles tratados anteriormente, ultrapassaria os limites deste artigo.

Assim, tendo em vista todas essas considerações aqui feitas, cabe concluir reiterando que, quando começamos a realizar um trabalho vocal, o potencial expressivo que comumente apresentamos é certamente muito mais reduzido que aquele que verdadeiramente possuímos, no que se refere tanto aos aspectos sonoros quanto aos demais aspectos expressivos do corpo. Geralmente, as dificuldades relacionadas ao não alcance de agudos e graves, à "projeção", referem-se à reação do corpo aos espaços e à velocidade do gesto vocal. Por isso, se a questão dos espaços, em especial do histórico e do mítico, não forem consideradas, de modo que o material expressivo reprimido seja finalmente libertado, o trabalho técnico desenvolvido, provavelmente, reforçará os limites existentes.

É inegável que, para o artista cênico, conquistar o espaço mítico é imprescindível. Por isso, ao me apropriar e disseminar a metodologia de Francesca Della Monica, o faço por percebê-la como uma estratégia pedagógica de extrema relevância para a formação e criação cênicas, uma vez que um de seus objetivos prin- 
cipais é estimular o rompimento das cercas que impedem a nossa expressão em sua plenitude, por meio de exercícios que, fazendo-nos ter acesso às áreas vocais de "perigo" - e, progressivamente, vencê-lo -, conduzem-nos corporalmente à conquista de espaço, ao alargamento de limites, à ampliação da gestualidade e da extensão vocal, ao resgate da identidade vocal e ao equilíbrio entre as expressões apolínea e dionisíaca da voz.

\section{Referências}

DELLA MONICA, Francesca; MALETTA, Ernani. Intorno agli spazi dell'azione vocale. In: MELLO, L. (Org) Teatro Laboratorio Toscana diretto da Federico Tiezzi, Pisa: Titivillus, 2013, p. 69-72.

DE MARINIS, Marco. Geroglifici del soffio: poesia-attore-voce fra Artaud e Decroux nel Novecento teatrale. Culture Teatrali: studi, interventi e scritture sullo spettacolo, Bologna, n. 20, p. 11-38, giugno, 2011.

MALETTA, Ernani. Estratégias pedagógicas polifônicas para a formação do ator. Belo Horizonte, 2011. Relatório de pesquisa e de atividades complementares (Pós-Doutorado) - Escola de Belas Artes, Universidade Federal de Minas Gerais.

ROSA, João Guimarães. A terceira margem do rio. In: ROSA, João Guimarães. Primeiras estórias. Rio de Janeiro: Nova Fronteira, 2001, p. 79-85. 